\title{
Multiple benefits of targeting inflammation in the treatment of type 2 diabetes
}

\author{
Marc Y. Donath ${ }^{1}$ \\ Received: 11 December 2015 /Accepted: 30 December 2015 /Published online: 11 February 2016 \\ (C) Springer-Verlag Berlin Heidelberg 2016
}

\begin{abstract}
The association between the metabolic syndrome and a pathological activation of the innate immune system is now well established. Thus, defective insulin secretion and action are due, at least in part, to islet, liver and fat inflammation in type 2 diabetes. Furthermore, an inflammatory process also seems to be involved in the development of cardiovascular, renal and ophthalmological complications of this disease. Interestingly, several other inflammatory diseases are associated with the metabolic syndrome, such as psoriasis, gout and rheumatic arthritis. The aim of this review is to discuss the clinical progress of anti-inflammatory drugs in the treatment of type 2 diabetes and then speculate on the possible further development of these drugs, with the aim of using the drugs in combination in order to combat the multiple manifestations of inflammatory diseases. This review summarises a presentation given at the 'Islet inflammation in type 2 diabetes' symposium at the 2015 annual meeting of the EASD. It is accompanied by two other reviews on topics from this symposium (by Simone Baltrusch, DOI: 10.1007/s00125-016-3891-x, and Jerry Nadler and colleagues, DOI: 10.1007/s00125-016-3890-y) and a commentary by the Session Chair, Piero Marchetti (DOI: 10.1007/s00125-016-3875-x).
\end{abstract}

Keywords Inflammation $\cdot$ Review $\cdot$ Treatment .

Type 2 diabetes

Marc Y. Donath

Marc.donath@usb.ch

1 Endocrinology, Diabetes \& Metabolism and Department of Biomedicine, University Hospital Basel,

CH-4031 Basel, Switzerland

\begin{abstract}
Abbreviations
CRP C-reactive protein

IL-1Ra IL-1 receptor antagonist

MCP-1 Monocyte chemoattractant protein-1
\end{abstract}

An increasing number of drugs are now available that can directly target various components of the immune system and have been shown to improve metabolism [1]. These are antibody-based molecules (e.g. IL-1 and TNF blockers) or small molecules (e.g. antagonists of CCL2, also termed monocyte chemoattractant protein-1 [MCP-1] and its receptor C-C motif chemokine receptor-2) that blocks cytokines or chemokines effects. Less specific (but not necessarily less effective) are other compounds, such as salsalate and diacerein. Clinical studies have validated the ability of these compounds to decrease glycaemia (see below). This effect seems to be due to different mechanisms with distinct effects on insulin secretion and insulin-sensitivity. Furthermore, some drugs may be more effective at tackling a specific diabetes complication. Finally, patients suffering from diabetesassociated diseases involving a specific immune pathway may experience improvements in both diabetes and these comorbidities, with a single drug.

\section{TNF}

In 1993, Hotamisligil and Spiegelman demonstrated TNF expression in adipose tissues of animal models of diabetes and linked this to insulin resistance [2]. This milestone study was the first demonstration that inflammation may be involved in the pathogenesis of type 2 diabetes. Unfortunately, the clinical translation of this discovery has been delayed following the contradictory findings of early proof-of- 
concept studies, which have since been found to have been subject to serious limitations in their study design. Indeed, these studies are characterized by small sample sizes and short duration that are insufficient to detect the expected changes [1, 3-6]. More recently, a study in obese individuals without diabetes demonstrated a decrease in fasting glucose following a 6-month inhibition of TNF [7]. Although it is likely that prolonged antagonism of TNF will improve diabetes, a state-of-the art clinical study of TNF antagonism is warranted in patients with type 2 diabetes.

\section{IL-1 $\beta$}

The first study to assign a role for IL- $1 \beta$ in the pathogenesis of type 2 diabetes demonstrated that IL- $1 \beta$ mediates the deleterious effects of high glucose on human beta cells [8]. This observation was supported by the findings of a study in which an animal model of diabetes received treatment with the SGLT2 inhibitor phlorizin, which normalised plasma glucose and prevented beta cell expression of IL-1 $\beta$ [8]. This was followed by a proof-of-concept study in patients with type 2 diabetes, which reported that blockade of IL-1 with its receptor antagonist IL-1Ra improves glycaemia and beta cell secretory function and reduces CRP levels [9]. Of note, 39 weeks after withdrawal of IL-1Ra, insulin secretion was still preserved and CRP levels remained decreased, suggesting that IL-1 antagonism has long-lasting effects [10], possibly because of an interruption of the vicious cycle of IL-1 $\beta$ autoinduction [11]. Twelve independent follow-up clinical studies have confirmed that IL-1 antagonism may improve insulin secretion or sensitivity and glycaemia [12]: ten in patients with type 2 diabetes, one in obese, insulinresistant, non-diabetic individuals with the metabolic syndrome [13] and one in insulin-resistant patients with type 1 diabetes [14].

\section{Salsalate}

In 2001, Shoelson and colleagues demonstrated that salsalate reverses hyperglycaemia in obese rodents by sensitising insulin signalling via inhibition of the nuclear factor- $\mathrm{KB}$ pathway [15]. This initial finding was then translated to the clinical situation by Goldfine, Shoelson and colleagues, from proofof-concept through to Phase III trials [16-19]. Most convincing are two multicentre, placebo-controlled studies which provide strong evidence that salsalate decreases systemic inflammation and improves glucose metabolism in patients with type 2 diabetes [20,21]. Importantly, the drug is cheap, has a high safety profile and is well-tolerated.

\section{Targeting macrophages}

The number and activity of macrophages are increased in adipose tissues and islets of patients with type 2 diabetes [22-24]. These tissue macrophages produce a significant proportion of the inflammatory factors that are upregulated by obesity. Accordingly, clinical studies targeting chemokines involved in the recruitment of these immune cells emerge as a valid approach to improve metabolism. Indeed, two recent clinical studies targeting MCP-1 or its receptor have reported that this approach improves glycaemia, apparently mainly via improved insulin secretion $[25,26]$. Interestingly, prolonged inhibition of MCP-1 activity led to improved albuminuria.

\section{Joining forces}

The aforementioned data support a role for inflammation in the pathogenesis of type 2 diabetes. The observed improvement in insulin secretion in response to treatment with certain drugs points to possible disease-modifying effects, i.e. prevention of the progressive decrease in insulin secretion and effectiveness. Treatments addressing inflammation may also protect organs typically affected by diabetes, i.e. kidney, eye and the cardiovascular system [27]. The Canakinumab Antiinflammatory Thrombosis Outcomes Study (CANTOS), a Phase III clinical trial of an anti-IL-1 $\beta$ antibody, is ongoing (ClinicalTrials.gov identifier: NCT01327846). The recruitment of 10,000 patients at risk of developing cardiovascular disease and diabetes to this large study is complete, and the study is designed to investigate the potential of IL- $1 \beta$ blockade to protect patients against cardiovascular disease and to prevent or ameliorate type 2 diabetes.

The interruption of vicious cycles of auto-inflammatory induction (e.g. IL- $1 \beta$-induced IL-1 $\beta$ release), and the long half-life of some (antibody-based) drugs explain the observed long-lasting effects. It is therefore conceivable that, after restoration of normoglycaemia and successful lifestyle changes, some patients may require a boost of anti-inflammatory drugs only a few times per year during recurrent flares.

The population of patients with type 2 diabetes is heterogeneous, with distinct genetic and behavioural backgrounds. Accordingly, genetic and biomarker analyses may be used to profile patients with type 2 diabetes to allow the prediction of those who would be expected to respond best to a specific anti-inflammatory drug.

Some immunomodulatory treatments (e.g. IL- $1 \beta$ and MCP-1 blockers) seem to predominantly improve insulin secretion, while others (e.g. TNF blockers and salsalate) may better target insulin resistance. Thus, the use of anti-inflammatory drugs in combination or sequentially may achieve broader and more profound effects in treating inflammation in patients with type 2 diabetes. 
The immune system appears to play a critical role in an increasing number of diseases [28]. Accordingly, numerous immunomodulating treatments are approved for a variety of indications. Understanding that the immune system is intimately linked to metabolism opens the door to novel therapeutic approaches. Thus, clinicians can focus on the pathologically activated pathways responsible for the disease (e.g. TNF- or IL-1-driven diseases) instead of focusing on the specific symptoms related to a definite area of medicine. In many cases, patients can already benefit from this thinking. Indeed, IL-1 $\beta$ is a critical mediator of gouty arthritis [29], and blocking IL-1 $\beta$ strongly improve this disorder [30]. Therefore in individuals affected from both type 2 diabetes and gout, IL-1 $\beta$ antagonism may ameliorate both maladies [31]. Diabetes is also often linked with TNF-driven illnesses, including rheumatoid arthritis, psoriasis and Crohn's disease. For these diseases, TNF blockade may be an attractive treatment to simultaneously treat these various manifestations of TNF over-activity [32]. Similarly, patients suffering from type 2 diabetes and joint pain may particularly benefit from the use of salsalate. The results of CANTOS (ClinicalTrials.gov identifier: NCT01327846) [33] will inform us whether a patient with cardiovascular diseases and type 2 diabetes may benefit from an anti-IL-1 $\beta$ treatment.

Duality of interest MYD is listed as the inventor on a patent (WO6709) filed in 2003 for the use of an IL-1 receptor antagonist for the treatment or prevention of type 2 diabetes and is a consultant for Novartis.

Contribution statement MYD was the sole contributor to this paper.

\section{References}

1. Donath MY (2014) Targeting inflammation in the treatment of type 2 diabetes: time to start. Nat Rev Drug Discov 13:465-476

2. Hotamisligil GS, Shargill NS, Spiegelman BM (1993) Adipose expression of tumor necrosis factor-alpha: direct role in obesitylinked insulin resistance. Science 259:87-91

3. Ofei F, Hurel S, Newkirk J, Sopwith M, Taylor R (1996) Effects of an engineered human anti-TNF-alpha antibody (CDP571) on insulin sensitivity and glycemic control in patients with NIDDM. Diabetes 45:881-885

4. Paquot N, Castillo MJ, Lefebvre PJ, Scheen AJ (2000) No increased insulin sensitivity after a single intravenous administration of a recombinant human tumor necrosis factor receptor: Fc fusion protein in obese insulin-resistant patients. J Clin Endocrinol Metab 85:1316-1319

5. Dominguez H, Storgaard H, Rask-Madsen C et al (2005) Metabolic and vascular effects of tumor necrosis factor-alpha blockade with etanercept in obese patients with type 2 diabetes. J Vasc Res 42: 517-525

6. Bernstein LE, Berry J, Kim S, Canavan B, Grinspoon SK (2006) Effects of etanercept in patients with the metabolic syndrome. Arch Intern Med 166:902-908
7. Stanley TL, Zanni MV, Johnsen S et al (2011) TNF- $\alpha$ antagonism with etanercept decreases glucose and increases the proportion of high molecular weight adiponectin in obese subjects with features of the metabolic syndrome. J Clin Endocrinol Metab 96:E146E150

8. Maedler K, Sergeev P, Ris F et al (2002) Glucose-induced beta-cell production of interleukin-1 beta contributes to glucotoxicity in human pancreatic islets. J Clin Invest 110:851-860

9. Larsen CM, Faulenbach M, Vaag A et al (2007) Interleukin-1receptor antagonist in type 2 diabetes mellitus. $\mathrm{N}$ Engl $\mathrm{J}$ Med $356: 1517-1526$

10. Larsen CM, Faulenbach M, Vaag A, Ehses JA, Donath MY, Mandrup-Poulsen T (2009) Sustained effects of interleukin-1 receptor antagonist treatment in type 2 diabetes. Diabetes Care 32: 1663-1668

11. Boni-Schnetzler M, Thorne J, Parnaud G et al (2008) Increased interleukin (IL)-1 $\beta$ messenger ribonucleic acid expression in betacells of individuals with type 2 diabetes and regulation of IL- $1 \beta$ in human islets by glucose and autostimulation. J Clin Endocrinol Metab 93:4065-4074

12. Herder C, Dalmas E, Boni-Schnetzler M, Donath MY (2015) The IL-1 pathway in type 2 diabetes and cardiovascular complications. Trends Endocrinol Metab 26:551-563

13. van Asseldonk EJ, Stienstra R, Koenen TB, Joosten LA, Netea MG, Tack CJ (2011) Treatment with Anakinra improves disposition index but not insulin sensitivity in nondiabetic subjects with the metabolic syndrome: a randomized, double-blind, placebo-controlled study. J Clin Endocrinol Metab 96:2119-2126

14. van Asseldonk EJ, van Poppel PC, Ballak DB, Stienstra R, Netea MG, Tack CJ (2015) One week treatment with the IL-1 receptor antagonist anakinra leads to a sustained improvement in insulin sensitivity in insulin resistant patients with type 1 diabetes mellitus. Clin Immunol 160:155-162

15. Yuan M, Konstantopoulos N, Lee J et al (2001) Reversal of obesityand diet-induced insulin resistance with salicylates or targeted disruption of $I k k \beta$. Science 293:1673-1677

16. Fleischman A, Shoelson SE, Bernier R, Goldfine AB (2008) Salsalate improves glycemia and inflammatory parameters in obese young adults. Diabetes Care 31:289-294

17. Goldfine AB, Silver R, Aldhahi W et al (2008) Use of salsalate to target inflammation in the treatment of insulin resistance and type 2 diabetes. Clin Transl Sci 1:36-43

18. Koska J, Ortega E, Bunt JC et al (2009) The effect of salsalate on insulin action and glucose tolerance in obese non-diabetic patients: results of a randomised double-blind placebo-controlled study. Diabetologia 52:385-393

19. Goldfine AB, Conlin PR, Halperin F et al (2013) A randomised trial of salsalate for insulin resistance and cardiovascular risk factors in persons with abnormal glucose tolerance. Diabetologia 56:714-723

20. Goldfine AB, Fonseca V, Jablonski KA et al (2010) The effects of salsalate on glycemic control in patients with type 2 diabetes: a randomized trial. Ann Intern Med 152:346-357

21. Goldfine AB, Fonseca V, Jablonski KA et al (2013) Salicylate (salsalate) in patients with type 2 diabetes: a randomized trial. Ann Intern Med 159:1-12

22. Ehses JA, Perren A, Eppler E et al (2007) Increased number of isletassociated macrophages in type 2 diabetes. Diabetes 56:2356-2370

23. Weisberg SP, McCann D, Desai M, Rosenbaum M, Leibel RL, Ferrante AW Jr (2003) Obesity is associated with macrophage accumulation in adipose tissue. J Clin Invest 112:1796-1808

24. Xu H, Barnes GT, Yang Q et al (2003) Chronic inflammation in fat plays a crucial role in the development of obesity-related insulin resistance. J Clin Invest 112:1821-1830

25. Di Prospero NA, Artis E, Andrade-Gordon P et al (2014) CCR2 antagonism in patients with type 2 diabetes mellitus: a 
randomized, placebo-controlled study. Diabetes Obes Metab 16:1055-1064

26. Haller HG, Menne J, Eulberg D (2015) CCL2 inhibition with emapticap pegol (NOX-E36) in type 2 diabetic patients with albuminuria. Diabetes 64(Suppl 1):A148, 580-P (Abstract)

27. Libby P, Ridker PM, Hansson GK, Leducq Transatlantic Network on A (2009) Inflammation in atherosclerosis: from pathophysiology to practice. J Am Coll Cardiol 54:2129-2138

28. Dinarello CA, Simon A, van der Meer JW (2012) Treating inflammation by blocking interleukin-1 in a broad spectrum of diseases. Nat Rev Drug Discov 11:633-652

29. Martinon F, Petrilli V, Mayor A, Tardivel A, Tschopp J (2006) Gout-associated uric acid crystals activate the NALP3 inflammasome. Nature 440:237-241
30. So A, de Smedt T, Revaz S, Tschopp J (2007) A pilot study of IL-1 inhibition by anakinra in acute gout. Arthritis Res Ther 9:R28

31. Vitale A, Cantarini L, Rigante D, Bardelli M, Galeazzi M (2015) Anakinra treatment in patients with gout and type 2 diabetes. Clin Rheumatol 34:981-984

32. Yeung H, Takeshita J, Mehta NN et al (2013) Psoriasis severity and the prevalence of major medical comorbidity: a population-based study. JAMA Dermatol 149:1173-1179

33. Ridker PM, Thuren T, Zalewski A, Libby P (2011) Interleukin-1 $\beta$ inhibition and the prevention of recurrent cardiovascular events: rationale and design of the Canakinumab Anti-inflammatory Thrombosis Outcomes Study (CANTOS). Am Heart J 162:597605 